\title{
Preparation of Cyclic Urethanes from Amino Alcohols and Carbon Dioxide Using Ionic Liquid Catalysts with Alkali Metal Promoters
}

\author{
Shin-ichiro Fujita *, Hiroshi Kanamaru, Hisanori Senboku and Masahiko Arai \\ Division of Chemical Process Engineering, Graduate School of Engineering, Hokkaido University, \\ Sapporo 060-8628, Japan \\ * Author to whom correspondence should be addressed; E-mail sfuji@ proc-ms.eng.hokudai.ac.jp
}

Received: 21 September 2006 / Accepted: 16 October 2006 / Published: 27 October 2006

\begin{abstract}
Several ionic liquids were applied as catalysts for the synthesis of cyclic urethanes from amino alcohols and pressurized $\mathrm{CO}_{2}$ in the presence of alkali metal compounds as promoters. A comparative study was made for the catalytic performance using different ionic liquids, substrates, promoters, and pressures. The optimum catalytic system was BMIM-Br promoted by $\mathrm{K}_{2} \mathrm{CO}_{3}$, which, for 1-amino-2-propanol, produced cyclic urethane in $40 \%$ yield with a smaller yield of substituted cyclic urea and no oligomeric byproducts. For other amino alcohols, cyclic urethanes, cyclic ureas, and/or undesired byproducts were produced in different yields depending on the substrates used. Possible reaction mechanisms are proposed.
\end{abstract}

Keywords: cyclic urethane, amino alcohol, carbon dioxide, ionic liquid catalyst, alkali promoter

\section{Introduction}

Cyclic urethanes are an important class of heterocyclic compounds, which have many biological applications. They are synthesized by reactions of amino alcohols with several different reagents such as phosgene [1], dialkyl carbonates [1-3], mixtures of carbon monoxide and oxygen via oxidative carbonylation [4-7], urea [8-10] and $\mathrm{CO}_{2}$ [11-18]. The dialkyl carbonates and oxidative carbonylation are currently in practical use. The use of phosgene and oxidative carbonylation is not eco-friendly due to risks associated with explosion hazards and poisonous phosgene or carbon monoxide. It should also 
be noted that dialkyl carbonates are currently produced via similar hazardous routes [19-22]. Reactions of amino alcohols with urea can produce cyclic urethanes with good yields [8-10]. However, these reactions will require the recovery of ammonia, if they are employed for the production of cyclic urethane in large scales. This can be an economical disadvantage of them. Under these circumstances, the reactions of amino alcohols with $\mathrm{CO}_{2}$ are preferable from environmental and economical viewpoints. Cyclic urethanes are produced from amino alcohols and $\mathrm{CO}_{2}$ even in the absence of catalysts, but, unfortunately, their yields are low [11,16,18]. Desirable high yields can be achieved by employing stoichiometrically consumed dehydration [12,13] or deoxygenation reagents [14,15]. However, the use of such indispensable reagents would raise the cost of the reaction processes. It was reported that triphenylstibine oxide [16,17] and dibutyltin oxide [18] could catalyze the synthesis of cyclic urethanes from amino alcohols and $\mathrm{CO}_{2}$. Although good yields were obtained with these catalysts, high reaction temperatures and/or long periods of reaction time were needed. Thus, the development of more efficient catalyst systems is still required.

In recent years, significant progress has been made in the application of ionic liquids as catalysts and alternative solvents in organic synthesis because they possess unique advantages of negligible vapour pressure, a broad range of room temperature liquid compositions, excellent thermal and chemical stabilities, interesting tunable physicochemical characteristics, and selective dissolvability to many organic and inorganic materials. The use of ionic liquids as reaction media and/or catalysts for clean catalytic transformations would indicate profound effects on the reaction rate and product selectivity. It has extensively been reviewed that catalytic activity and product selectivity are accelerated and controlled when they are used for hydrogenation, oxidation, alkylation, hydroformylation, and Heck and Suzuki coupling reactions [23-27]. Additionally, if the synthesis is carried out with an ionic liquid catalyst and the products are immiscible with it, the catalyst separation and recycling are easy. It has also been reported that $\mathrm{CO}_{2}$ are significantly soluble into the ionic liquid phase, which, therefore, makes the reactions of $\mathrm{CO}_{2}$ in it possible and suitable [28,29].

As recently reviewed [30], the utilization of ionic liquids for the cycloaddition of $\mathrm{CO}_{2}$ to epoxides to produce cyclic carbonates has been extensively studied. In contrast, only a few authors used ionic liquids as catalysts and reaction media for the production of cyclic urethanes [31,32]. Kawanami et al. reported the effectiveness of $[\mathrm{TOA}]^{+}[\mathrm{TFSI}]^{-}$(or [TSAC]) (TOA: tetraoctyl ammonium; TFSI: bis(trifluoromethylsulfonyl)imide; TSAC: (2,2,2-trifluoro-N-(trifluoromethylsulfonyl)acetamide) for the synthesis of cyclic urethanes from aziridines and $\mathrm{CO}_{2}$ [31]. The reactions are conducted in a volume of the ionic liquids under high-pressure $\mathrm{CO}_{2}$ and are completed with excellent yields in such a short time of $<10 \mathrm{~min}$ at a low temperature of $40^{\circ} \mathrm{C}$. Deng et al. used copper halides and ionic liquids (solvents) for the synthesis of cyclic urethanes from amines, propargylic alcohols, and $\mathrm{CO}_{2}$ [33]. They showed good yields with catalytic amounts of copper halides in $10 \mathrm{~h}$ at $100^{\circ} \mathrm{C}$. In addition, they reported the effectiveness of $\mathrm{CsOH}$ addition in the synthesis of urea derivatives from amines and $\mathrm{CO}_{2}$ in the presence of ionic liquid catalysts [33]. To our knowledge, no study has so far been made to examine the use of ionic liquids as catalysts for the synthesis of cyclic urethanes from amino alcohols and $\mathrm{CO}_{2}$ (Scheme 1). In the present work, the authors have applied several ionic liquids in the presence and absence of alkali metal promoters for this reaction. The influence of ionic liquids, alkali metal compounds, reaction conditions and amino alcohols on the total conversion and the product selectivity 
has been examined in the absence of any dehydrating agents and the reaction paths and mechanisms have been discussed. This is a part of our study on the chemical fixation of $\mathrm{CO}_{2}$ into valuable organic compounds such as carbonates, urethanes, ureas, and so on using multiphase catalytic reactions $[30,34,35]$.

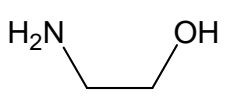

1

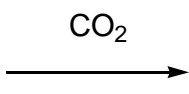

Scheme 1. Synthesis of cyclic urethane from amino alcohol and $\mathrm{CO}_{2}$.

\section{Results and Discussion}

\subsection{Activity of different ionic liquids}

Several ionic liquids as given in Table 1 were screened for the reaction of 2 -aminoethanol 1 and $\mathrm{CO}_{2}$ under certain conditions. 2-Oxazolidinone 2 and 1-(2-hydroxyethyl)-2-imidazolidinone 3 were observed to form along with other oligomeric heavier products. Fig. 1 shows the significant influence of different ionic liquid catalysts on the reaction. In conformity with the previous results $[11,16,18]$, the yields of $\mathbf{2}$ and $\mathbf{3}$ are low in the absence of the ionic liquids. These yields increase in the presence of the ionic liquids. The type of cations and anions of the ionic liquids have a strong impact on the product selectivity rather than the total conversion. It is indicated that TBPB gives a larger yield of $\mathbf{2}$ by a factor of 2 compared with TBAB, the more electropositive center $\left(\mathrm{P}^{+}\right)$being better than the less electropositive one $\left(\mathrm{N}^{+}\right)$. Similar yields of $\mathbf{2}$ were obtained with TBPB and BMIM-Br but the yield of 3 was larger with the latter. A larger yield of 2 was also observed with BMIM-PF ; however, the

Table 1. Ionic liquids used as catalysts for the synthesis of cyclic urethanes from amino alcohols and carbon dioxide

\begin{tabular}{lll}
\hline Cation & Anion $\left(\mathrm{X}^{-}\right)$ & Abbreviation \\
\hline BMIM-X (R = Butyl) \\
OMIM-X (R= Octyl)
\end{tabular}


reaction mixture changed into a gel after the reaction and it was difficult to treat and use further. BMIM-BF 4 was selective to the formation of $\mathbf{3} . \mathrm{OMIM}_{4}-\mathrm{BF}_{4}$ gave similar small yields of $\mathbf{2}$ and $\mathbf{3}$ with a larger yield of undesired byproducts. Thus, BMIM-Br has been used to examine reaction conditions and mechanisms in the following runs.

In a separate run, the reaction was carried out in the absence of ethanol. Under this condition, the total yield of oligomeric byproducts was larger, probably because of a higher substrate concentration. So, dilution using a solvent would be important to avoid the formation of undesired byproducts.

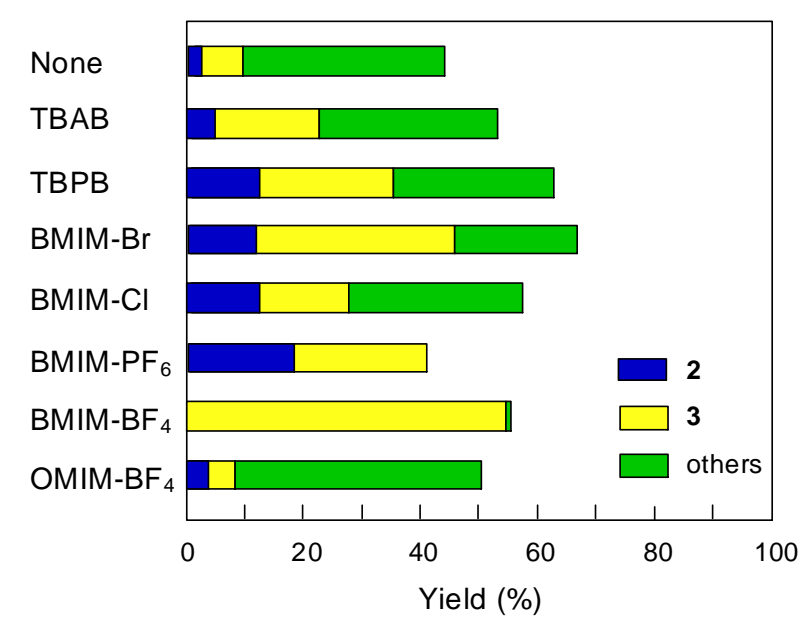

Figure 1. Reaction of $\mathrm{CO}_{2}$ with 2-aminoethanol in the presence of various ionic liquids. Reaction conditions: 2-aminoethanol, $60 \mathrm{mmol} ; \mathrm{CO}_{2} 10 \mathrm{MPa}$; ethanol, $4 \mathrm{~cm}^{3}$; ionic liquid, $11.4 \mathrm{mmol}$; temperature, $150^{\circ} \mathrm{C}$; time, $6 \mathrm{~h}$.

\subsection{Additive effects of alkali metal compounds}

Deng et al. reported the effectiveness of $\mathrm{CsOH}$ addition to ionic liquid catalysts for the synthesis of urea derivatives from amines and $\mathrm{CO}_{2}$ [33]. In the present work, attempts were made to add alkali metal compounds to improve the performance of BMIM-Br catalyst. Table 2 gives the results of reactions of 1 and $\mathrm{CO}_{2}$ in the presence of several carbonates and hydroxides. These additives affect the total conversion of $\mathbf{1}$ but not so markedly. It is noteworthy that the addition of $\mathrm{K}_{2} \mathrm{CO}_{3}$ enhances the yields of $\mathbf{2}$ and $\mathbf{3}$, more significantly for $\mathbf{2}$, and stops the formation of undesired oligomeric products, compared with the results obtained in the presence of BMIM- $\mathrm{Br}$ alone. $\mathrm{K}_{2} \mathrm{CO}_{3}$ is a much better promoter than the other additives of $\mathrm{Li}_{2} \mathrm{CO}_{3}, \mathrm{Cs}_{2} \mathrm{CO}_{3}, \mathrm{KOH}$ and $\mathrm{CsOH}$ examined, which give large amounts of undesired oligomeric byproducts. In the work of Deng et al., $\mathrm{KOH}$, a weaker base, was found to be less effective for their urea synthesis than $\mathrm{CsOH}$ [33].

\subsection{Influence of $\mathrm{CO}_{2}$ pressure and reaction paths}

The reaction of 1 with $\mathrm{CO}_{2}$ was run at different $\mathrm{CO}_{2}$ pressures in the presence of BMIM-Br and $\mathrm{K}_{2} \mathrm{CO}_{3}$ promoter. As shown in Fig. 2, the total conversion depends slightly on the pressure but the yield of 2 significantly increases to a maximum at around $10 \mathrm{MPa}$, at which no oligomeric byproducts 
Table 2. Additive effects of alkaline carbonates and hydroxides on the reaction ${ }^{\mathrm{a}}$ of 2 -aminoethanol $\mathbf{1}$ and carbon dioxide in the presence of BMIM-Br

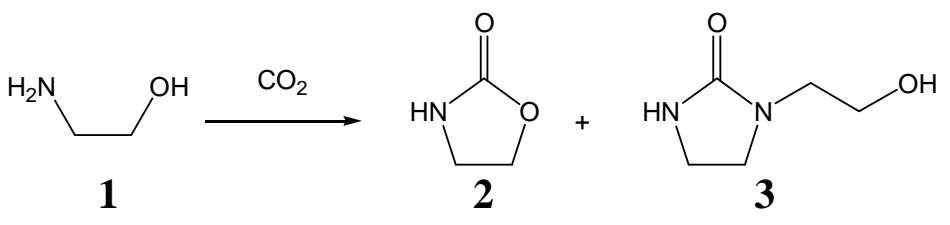

\begin{tabular}{ccccc}
\hline Additive & Conversion & \multicolumn{3}{c}{ Selectivity $(\%)$} \\
\cline { 3 - 5 } & $(\%)$ & $\mathbf{2}$ & $\mathbf{3}$ & Others \\
\hline- & 67 & 18 & 51 & 31 \\
$\mathrm{LiCO}_{3}$ & 68 & 15 & 40 & 45 \\
$\mathrm{~K}_{2} \mathrm{CO}_{3}$ & 55 & 34 & 66 & 0 \\
$\mathrm{Cs}_{2} \mathrm{CO}_{3}$ & 66 & 15 & 35 & 50 \\
$\mathrm{KOH}$ & 59 & 17 & 38 & 45 \\
$\mathrm{CsOH}$ & 68 & 15 & 62 & 22 \\
\hline
\end{tabular}

${ }^{\text {a }}$ Reaction conditions: 2-aminoethanol $60 \mathrm{mmol}, \mathrm{CO}_{2} 10 \mathrm{MPa}$, ethanol $4 \mathrm{~cm}^{3}$, BMIM-Br $11.4 \mathrm{mmol}$, additive $0.7 \mathrm{mmol}, 150{ }^{\circ} \mathrm{C}, 6 \mathrm{~h}$.

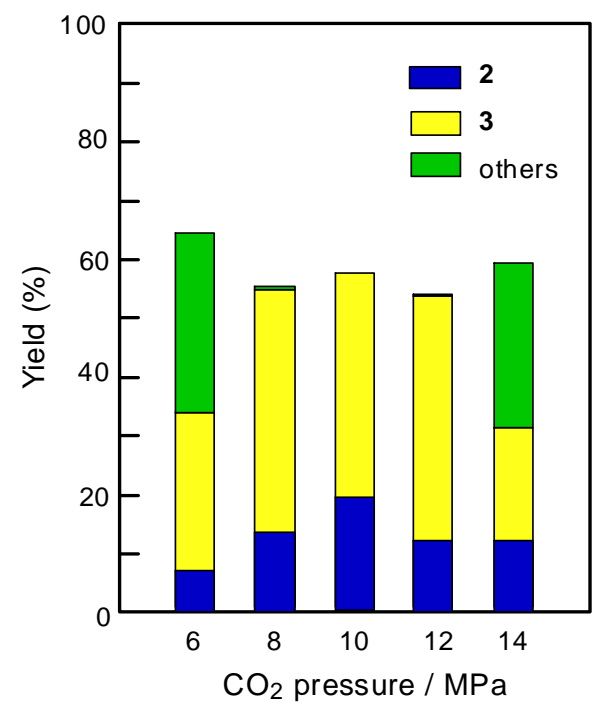

Figure 2. Influence of $\mathrm{CO}_{2}$ pressure on the reaction of $\mathrm{CO}_{2}$ and 2-aminoethanol. Reaction conditions: 2-aminoethanol, $60 \mathrm{mmol}$; ethanol, $4 \mathrm{~cm}^{3}$; $\mathrm{BMIM}-\mathrm{Br}, 11.4 \mathrm{mmol} ; \mathrm{K}_{2} \mathrm{CO}_{3}, 0.7 \mathrm{mmol}$; temperature, 150 ${ }^{\circ} \mathrm{C}$; time, $6 \mathrm{~h}$.

were observed to form. The yield of $\mathbf{3}$ is less dependent on the pressure compared with $\mathbf{2}$. At a higher pressure of $14 \mathrm{MPa}$, the oligomeric byproducts are formed again and the yields of $\mathbf{2}$ and $\mathbf{3}$ are reduced. Under the conditions used, the optimum pressure of $\mathrm{CO}_{2}$ is $10 \mathrm{MPa}$ with respect to the formation of 2 . The phase behavior is important for multiphase reactions using pressurized $\mathrm{CO}_{2}$ and it was examined by the naked eye. For the liquid mixture of the substrate $\mathbf{1}$ and the solvent, ethanol, at the reaction temperature, the gas and liquid phases were found to coexist at pressures up to $30 \mathrm{MPa}$. Thus, the 
reaction should occur under biphasic conditions; the substrate, the ionic liquid catalyst, and the promoter are mainly dissolved in the liquid phase, in which $\mathrm{CO}_{2}$ is also soluble, and the gas phase is a reservoir of $\mathrm{CO}_{2}$. The main reaction phase is the liquid (ethanol) phase at $\mathrm{CO}_{2}$ pressures used in the present work.

Fig. 3 shows the changes of total conversion and product yields with reaction time. The yield of 2 increases during the initial period of time and then gradually decreases while the yield of $\mathbf{3}$ simply increases with time. In a separate run using the substrate $\mathbf{1}$ and the product $\mathbf{2}$ in the absence of $\mathrm{CO}_{2}$, the compound $\mathbf{3}$ was observed to form at the expense of $\mathbf{1}$. Thus, there occur consecutive reactions that $\mathbf{1}$ reacts with $\mathrm{CO}_{2}$ producing 2 and then 2 reacts with 1 giving 3 (Scheme 2) and these two reactions proceed in parallel. It is difficult at present to clearly explain the pressure dependence shown in Fig. 2 but it could be ascribable to negative and positive effects of pressurized $\mathrm{CO}_{2}$. Increasing $\mathrm{CO}_{2}$ pressure may increase the concentration of $\mathrm{CO}_{2}$ in the liquid phase but decreases the substrate concentration; the former promotes the formation of $\mathbf{2}$ but not of $\mathbf{3}$; in addition, higher $\mathrm{CO}_{2}$ pressures may stop the formation of oligomeric byproducts.

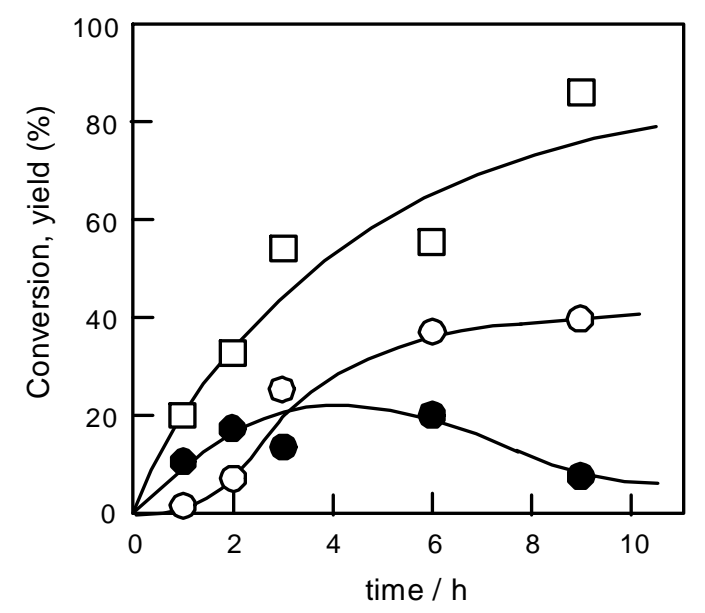

Figure 3. Changes of total conversion and product yields with reaction time. Conversion, ( $\square$ ); yields of $2(\bigcirc)$ and $3(\bigcirc)$.

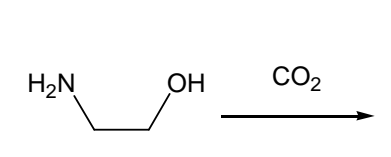

1<smiles>O=C1NCCO1</smiles>

2

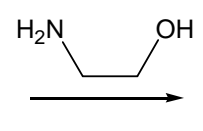

$\overbrace{1}^{O}$

3

Scheme 2. Consecutive transformation from 2-aminoethanol 1 to 2 -oxazolidinone 2 and then to 1-(2hydroxyethyl)-2-imidazolidinone 3 . 


\subsection{Application to different amino alcohols}

The optimum catalyst system of BMIM-Br with $\mathrm{K}_{2} \mathrm{CO}_{3}$ has been applied for other different amino alcohols as shown in Scheme 3. The catalytic performance was shown to strongly depend on the structure of the substrates used (Fig. 4). For 1c, a better yield of cyclic urethane $2 \mathbf{c}$ was obtained along with a smaller yield of cyclic urea 3c. A similar cyclic urethane (2d) yield was shown with $\mathbf{1 d}$ but a larger amount of cyclic urea $\mathbf{3 d}$ was produced with a detectable amount of oligomeric byproducts. For $\mathbf{1 a}$ and $\mathbf{1 b}$, the cyclic urethanes $\mathbf{2 a}$ and $\mathbf{2 b}$ were produced in smaller quantities, compared with $\mathbf{1 c}$ and 1d; for the former substrate, a large amount of cyclic urea (3a) was formed with no other products; for the latter, cyclic urea $\mathbf{3 b}$ was obtained in a small amount with a large amount of other byproducts. For secondary amino alcohols $\mathbf{1 e}$ and $\mathbf{1 f}$, cyclic urethanes were observed to form with increased quantities of oligomeric byproducts but no corresponding cyclic ureas were detected.

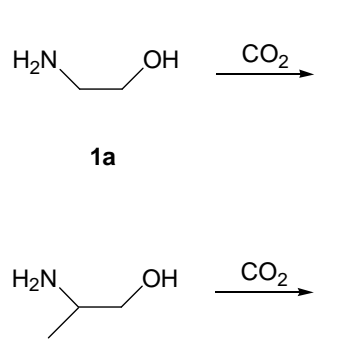

1b

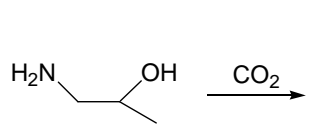

$1 c$

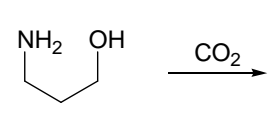

$1 d$

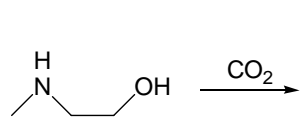

$1 \mathrm{e}$

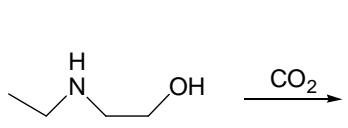

16

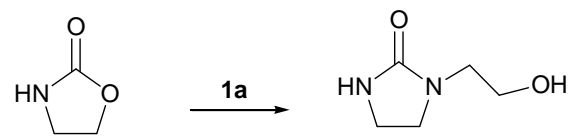

2a (20\%)

3a (38\%)

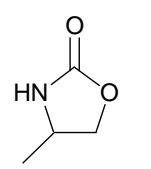

2b (23\%)

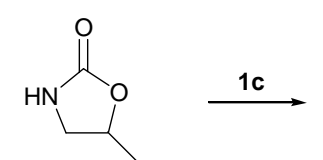

2c (37\%)

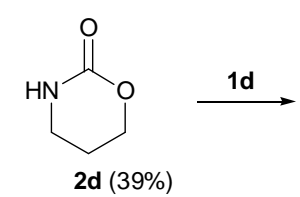

${ }_{1}^{O}$

2e (12\%)

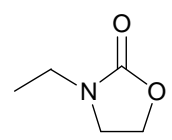

2 f $(17 \%)$

Scheme 3. Reactions of $\mathrm{CO}_{2}$ with various amino alcohols. Product yields were given in the parentheses. 


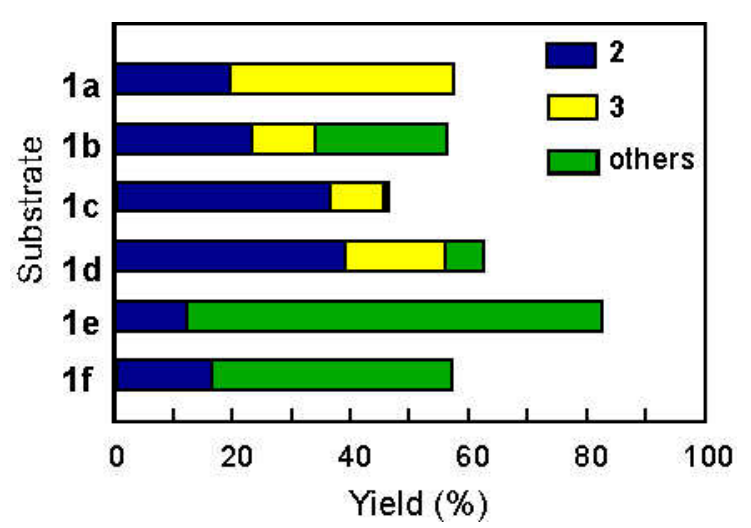

Figure 4. Reactions of $\mathrm{CO}_{2}$ with various amino alcohols. Reaction conditions: amino alcohol, 60 mmol; $\mathrm{CO}_{2} 10 \mathrm{MPa}$; ethanol, $4 \mathrm{~cm}^{3}$; $\mathrm{BMIM}-\mathrm{Br}, 11.4 \mathrm{mmol} ; \mathrm{K}_{2} \mathrm{CO}_{3}, 0.7 \mathrm{mmol}$; temperature, $150^{\circ} \mathrm{C}$; time, $6 \mathrm{~h}$.

Nomura et al. used a homogeneous catalyst of triphenylstibine oxide for the synthesis of cyclic urethanes from several amino alcohols and $\mathrm{CO}_{2}$ [16]. This catalyst gave low yields of cyclic urethanes from 2-aminoethanol and 1-amino-2-propanol even in the presence of molecular sieve 3A as a dehydration agent at $160^{\circ} \mathrm{C}$ for $6 \mathrm{~h}$ under compressed $\mathrm{CO}_{2}(5 \mathrm{MPa}$ at room temperature). For these substrates, the stibine oxide catalyst is not effective compared with BMIM-Br. However, when 2methylamino-ethanol and 1-methylamino-2-propanol were used as the starting amino alcohols, the oxide catalyst gave moderate yields of corresponding cyclic urethanes. Similar influence of Nalkylation on the cyclic urethane yield was also reported by Tominaga and Sasaki who used dibutyltin oxide $\mathrm{n}-\mathrm{Bu}_{2} \mathrm{SnO}$ as the catalyst in an organic solvent of NMP [18]. Cyclic urethane was obtained from 2-methylamino-ethanol at a yield above $90 \%$ in a long time of $16 \mathrm{~h}$ at a higher temperature of $180^{\circ} \mathrm{C}$. However, the yield of cyclic urethane decreased to 53\%, when 2-aminoethanol was used as the substrate. Thus, the effects of $\mathrm{N}$-alkylation of amino alcohol in the presence of these oxide catalysts are different from that in the presence of BMIM-Br (Fig. 4).

Those results demonstrate that the present catalyst systems can produce cyclic urethanes from amino alcohols and $\mathrm{CO}_{2}$, which are more eco-friendly compared with the previous reaction systems using harmful reagents such as phosgene and carbon monoxide [1,4-7]. For the practical green production of cyclic urethanes, the separation and recycling of catalysts are an important issue. To examine the separation of the catalyst by extraction from the products, we measured those solubilities into several organic solvents. Unfortunately, among the solvents tested (acetone, dichloromethane, diethyl ether, ethyl acetate, dimethylformamide, $N$-methylpyrrolidone, hexane, toluene), good solvents for BMIM-Br were also good ones for the products. So, the separation of the catalyst by simple extraction is difficult even after removing the reaction solvent of ethanol and unreacted aminoethanol by evaporation. The catalyst separation would be possible by fractional distillation and/or column chromatography. The dispersion of catalytically active components (ionic liquids and alkali metals) on a solid surface as in supported liquid phase catalysts [36] could be another possible way for the separation and recycling, which will be the subject of future research. 


\subsection{Reaction mechanisms}

Although the details of catalytic function of the ionic liquids and alkali metal promoters are unknown, brief consideration is given here to reaction mechanisms. A possible mechanism for the formation of cyclic urethane from amino alcohol is illustrated in Scheme 4. It is known that carbamic acid is easy to form by interaction of $\mathrm{NH}_{2}$ group with a $\mathrm{CO}_{2}$ molecule. It has been reported that imidazolium salts and imidazolium cations can act as Lewis acids and/or anion receptors [37-39]. Therefore, the coordination of the imidazoliun caion to the carbonyl group of the carbamic acid would be likely to occur (step 3). This produces a reactive intermediate $\mathbf{4}$, which could be converted to a cyclic intermediate $\mathbf{5}$ by the intramolecular attack of alcoholic hydroxyl group (step 4). The intermediate 5 can be converted to cyclic urethane by dehydration. In the case of the reaction with either 1e or 1f, the yields of urethanes are lower (Fig. 4). These results would be caused by a steric hindrance effect, resulting from bulkiness of secondary amines $\mathbf{1 e}$ and $\mathbf{1 f}$ as a nucleophile, on the first steps in Scheme 4.

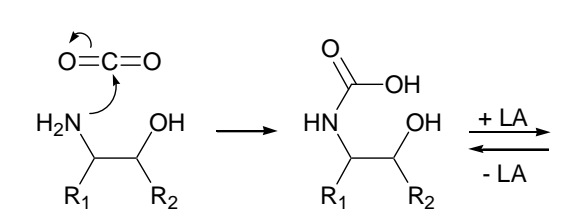

$\mathrm{LA}=$ imidazolium cation

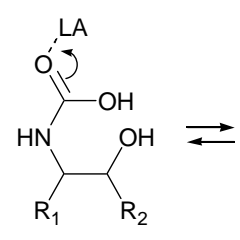$$
\text { (1) }
$$

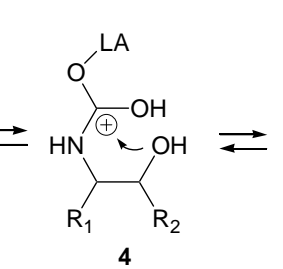

4

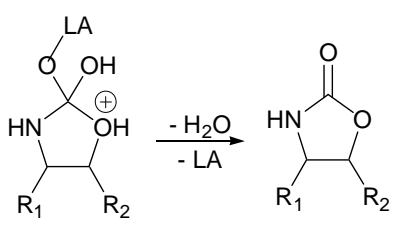

5

Scheme 4. A possible mechanism for the formation of cyclic urethane from amino alcohol.

Scheme 5 also gives a possible mechanism for the further change of cyclic urethane with amino alcohol substrate to substituted cyclic urea. The first step is the ring opening through nucleophilic attack of nitrogen of amino alcohol to the carbon atom at $\mathrm{C}_{5}$ position of the ring, giving a substituted carbamic acid 6. As a similar manner in the formation of urethanes, the carbamic acid would be coordinated again by imidazolium cation to form a reactive intermediate 7 and this species could be transformed to the substituted cyclic urea thorough the formation of a cyclic intermediate $\mathbf{8}$ followed by dehydration. For 1c and 1d, the yields of cyclic urea are smaller compared with 1a (Fig. 4); for 1c, the smaller yield of cyclic urea is ascribable to a steric hindrance effect on the first step in Scheme 5, resulting from the presence of methyl group at $\mathrm{C}_{5}$ position of the oxazolidinone $\mathbf{2 c}$; for $\mathbf{1 d}$, the smaller yield may be ascribed to that the six-membered ring of $\mathbf{2 d}$ is more stable than the five-membered ring of $\mathbf{2 a}$, resulting in a slower rate of the first step.

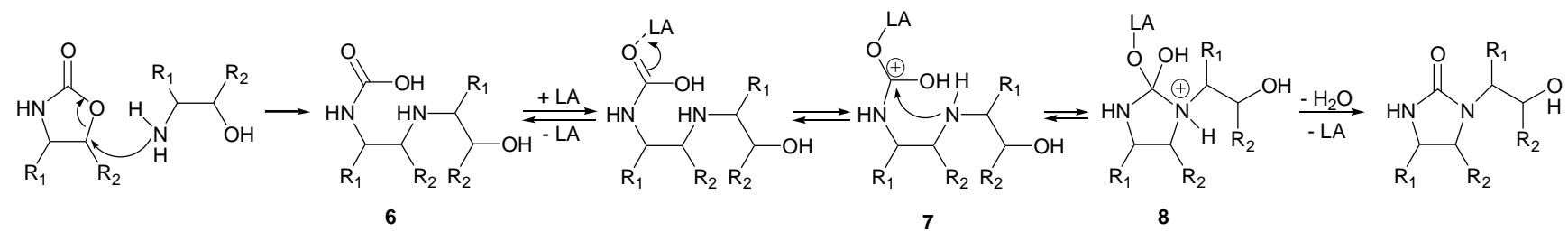

Scheme 5. A possible mechanism for the formation of substituted cyclic urea from cyclic urethane. 
In conclusion, a two-component catalytic system of BMIM-Br with a promoter of $\mathrm{K}_{2} \mathrm{CO}_{3}$ is effective for the transformation of amino alcohols with pressurized $\mathrm{CO}_{2}$ to cyclic urethanes and ureas. The catalytic performance of this catalyst system strongly depends on the structure of substrates used. For 1-amino-2-propanol (1c) under optimized conditions, a high yield of the cyclic urethane (2c) of $40 \%$ is obtained along with the substituted cyclic urea (3c) in a yield of $10 \%$. It is important to note that no undesired oligomeric products are formed with this substrate. For 2-aminoethanol (1a), cyclic urethane (2a) and cyclic urea (3a) are produced in comparable yields with no other byproducts. For 3amino-1-propanol (1d), the yield of the desired product (2d) is good with smaller yields of the cyclic urea (3d) and other byproducts. For other amino alcohols examined, significant amounts of undesired oligomeric compounds are produced. After considering those results, possible reaction mechanisms are suggested for the formation of cyclic urethanes and cyclic ureas. In the present study, only ethanol was employed as the solvent, because it dissolves the catalyst and the substrate, resulting in a good mixing of them. Additionally, ethanol is also a good solvent for the product cyclic compounds. This makes it easier to treat the reaction mixture for the product analysis. However, the influence of the solvent on the reaction is an important issue, which will be examined in near future.

\section{Experimental Section}

All chemicals were purchased from Wako and Fluka and used without further purification. All reaction runs were carried out in a $50 \mathrm{~cm}^{3}$ autoclave with a mechanical agitator. In a typical run, the reactor was charged with the ionic liquid $(11.4 \mathrm{mmol})$, substrate $(60 \mathrm{mmol})$ and ethanol $\left(4 \mathrm{~cm}^{3}\right)$ and purged with $\mathrm{CO}_{2}$ a few times at atmospheric pressure. The reactor was heated to $150^{\circ} \mathrm{C}$ and then $\mathrm{CO}_{2}$ was further injected up to $6 \mathrm{MPa}$ under stirring. The reaction mixture was stirred for $6 \mathrm{~h}$ and then the reactor was cooled to room temperature and depressurized. The liquid reaction mixture was diluted with ethanol to $50 \mathrm{~cm}^{3}$ and analyzed by a gas chromatogragh (GL Science GC-390B) with a flame ionization detector. The results were also confirmed by a gas chromatograph coupled with a mass spectrometer (Shimadzu GC-MS QP5050A). For the reaction of 2-aminoethanol 1 and $\mathrm{CO}_{2}$, for example, we observed the formation of 2-oxazolidinone $\mathbf{2}$ and 1-(2-hydroxyethyl)-2-imidazolidinone 3. The yield of $\mathbf{2}$ (or $\mathbf{3}$ ) was determined by (the amount of $\mathbf{2}$ (or 3) formed) / (the initial amount of $\mathbf{1}$ used). However, the mass balance of the reaction was sometimes not good depending on the catalyst, reaction conditions and the substrate. We analyzed the reaction mixture by GC-MS; however, no peaks for high boiling products were observed even when a non-polar capillary column was used for the analysis. Furthermore, the reaction mixtures were sometimes slightly sticky. So, it was concluded oligomers of the substrate and/or the products that could not be extruded from the column were formed along with 2 and 3. Thus, the structures and yields of the origomeric byproducts could not be determined. So, for convenience, the $\%$ yield of the oligomeric products was calculated by 100 - the summed $\%$ yields of 2 and 3. The phase behavior of reaction mixtures was examined by the naked eye with another $10 \mathrm{~cm}^{3}$ autoclave with sapphire windows $[40,41]$ using the same volume ratio of reacting species as used for the reaction runs. 


\section{References}

1. Newman, M. S.; Kutner, A. New Reactions Involving Alkaline Treatment of 3-Nitroso-2oxazolidones. J. Am. Chem. Soc. 1951, 73, 4199-4204.

2. Fu, Y.; Baba, T.; Ono, Y. Carbonylation of $o$-Phenylenediamine and $o$-Aminophenol with Dimethyl Carbonates Using Lead Compounds as Catalysts. J. Catal. 2001, 197, 91-97.

3. Vani, P. S. N.; Chida, A. S.; Srinivasan, R.; Chandrasekharam, M.; Singh, A. K. Synthesis of Nvinyl-2-oxazolidone: A Commercially Important Intermediate. Syn. Commun. 2001, 31, 20432046.

4. Yoshida, T.; Kambe, N.; Murai, S.; Sonoda, N. A New synthesis of Cyclic Ureas, Cyclic Urethanes, and a Quinazolinedone. Selenium-Assisted Carbonylation of Aromatic Amine with Carbon Monoxide. Bull. Chem. Soc. Jpn. 1987, 60, 1793-1799.

5. Imada, Y.; Mitsue, Y.; Ike, K.; Washizuka, K.; Murahashi, S. Palladium-Catalyzed Double and Single Carbonylations of $\beta$-Amino Alcohols. Selective Synthesis of Morpholine-2,3-diones and Oxazolidin-2-ones and Applications for Synthesis $\alpha$-Oxo Carboxylic Acids. Bull. Chem. Soc. Jpn. 1996, 69, 2079-2090.

6. Gabriele, B.; Salerno, G.; Brindisi, D.; Costa, M.; Chiusoli, G. P. Synthesis of 2-Oxazolidinones by Direct Palladium Catalyzed Oxidative Carbonylation of 2-Amino-1-alkanols. Org. Lett. 2000, 2 , 625-627.

7. Gabriele, B.; Mancuso, R.; Salerno, G.; Costa, M. An Improved Procedure for the PalladiumCatalyzed Oxidative Carbonylation of $\beta$-Amino Alcohols to Oxiazokidin-2-ones J. Org. Chem. 2003, 68, 601-604.

8. Close, W. J.; Tiffany, B. D.; Spielman, M. A. The Analgestic Activity of Some Benzoxazolone Derivatives. J. Am Chem. Soc. 1949, 71, 1265-1268.

9. Close, W. J. Antivulsant Drigs. IV Some- 2-Oxazolidones. J. Am. Chem. Soc. 1951, 73, 95-98.

10. Bhanage, B. M.; Fujita, S.; Ikushima, Y.; Arai, M. Non-catalytic Clean Synthesis Route Using Urea to Cyclic Urea and Cyclic Urethane Compounds. Green Chem. 2004, 5, 429-432.

11. Bhanage, B. M.; Fujita, S.; Ikushima, Y.; Arai, M. Synthesis of Cyclic Ureas and Urethanes from Alkylene Diamines and Amino Alcohols with Pressurized Carbon Dioxide in the Absence of Catalysts. Green Chem. 2003, 5, 340-343.

12. Dozen, Y.; Ukita, M. Preparation of 2-Oxazolidinones. Jpn. Kokakai 1982, JP 5742678.

13. Kawanami, H.; Ikushima, Y. Synthesis of 2-Oxazolidinone from $\beta$-Aminoalcohol Using Supercritical Carbon Dioxide. J. Jpn. Petrol. Inst. 2002, 45, 321-324.

14. Kodaka, M.; Tomihiro, T.; Lee, A. L.; Okuno, H. Carbon Dioxide Fixation Forming Oxazolidone Coupled with a Thiol/ $/ \mathrm{Fe}_{4} \mathrm{~S}_{4}$ Cluster Redox System. J. Chem. Soc. Chem. Commun. 1989, 14791481.

15. Kubota, Y.; Kodaka, M.; Tomohiro, T.; Okuno, H. Formation of Cyclic Urethanes from Amno Alcohols and Carbon Dioxide Using Phosphorous(III) Reagents and Halogenoalkanes. J. Chem. Soc. Perkin Trans. I 1993, 5-6.

16. Matsuda, H.; Baba, A.; Nomura, R.; Kori, M.; Ogawa, S. Improvement of the Process in the Synthesis of 2-Oxazolidinones from 2-Amino Alcohols and Carbon Dioxide by Use of Triphenylstibine Oxide as Catalyst. Ind. Eng. Chem. Prod. Res. Dev. 1985, 24 239-242. 
17. Nomura, R.; Yamamoto, M.; Matsuda, H. Preparation of Cyclic Ureas from Carbon Dioxide and Diamines Catalyzed by Triphenylstibine Oxide. Ind. Eng. Chem. Res. 1987, 26, 1056-1059.

18. Tominaga, K.; Sasaki, Y. Synthesis of 2-Oxazolidinones from $\mathrm{CO}_{2}$ and 1,2-Aminoalcohols Catalyzed by $n-\mathrm{Bu}_{2} \mathrm{SnO}$. Synlett 2002, 307-309.

19. Ono Y. Catalysis in the production and reactions of dimethyl carbonate, an environmentally benign building block. Appl. Catal. A: Gen. 1997, 155, 133-166.

20. Ono, Y. Dimethyl carbonate for environmentally benign reactions. Catal. Today 1997, 35, 15-25.

21. Pacheco, M. A.; Marshall, X. L. Review of Dimethyl Carbonate Manufacture and Its Characteristics as a Fuel Additive. Energy Fuels 1997, 11, 2-29.

22. Delledonne, D.; Rivetti, F.; Romano, U. Developments in the production and application of dimethylcarbonate. Appl. Catal. A: Gen. 2001, 221, 241-251.

23. Sheldon, R. Catalytic reactions in ionic liquids. Chem. Commun. 2001, 2399-2407.

24. Zhao, D. B.; Wu, M.; Kou, Y.; Min, E. Ionic liquids: application in catalysis. Catal. Today 2002, 74, 157-189.

25. Wasserscheid, P.; Keim, W. Ionic Liquids-New "Solutions" for Transition Metal Catalysis. Angew. Chem. Int. Ed. 2000, 39, 3772-2789.

26. Dupont, J.; de Souza, F.; Suarez, P. A. Z. Ionic Liquid (Molten Salt) Phase Organometallic Catalysis. Chem. Rev. 2002, 102, 3667-3692.

27. Holbrey, J. D.; Seddon, K. R. Ionic Liquids. Clean Prod. Process. 1999, 1, 223-236.

28. Blanchard, L. A.; Hancu, D.; Beckman, E. J.; Brennecke J. F. Green processing using ionic liquids and $\mathrm{CO}_{2}$. Nature 1999, 399, 28-29.

29. Anthony, J. L.; Maginn, E. J.; Brennecke, J. F. Solubilities and Thermodynamic Properties of Gases in the Ionic Liquid 1-n-Butyl-3-methylimidazollium Hexafluorophosphate. J. Phys. Chem. B 2002, 106, 7315-7320.

30. Sun, J.; Fujita, S.; Arai, M.; Development in the Green Synthesis of Cyclic Carbonate Using Ionic Liquids. J. Organomet. Chem. 2005, 690, 3490-3497.

31. Kawanami, H.; Matsumoto, H.; Ikushima, Y. Effective $\mathrm{scCO}_{2}$-ionic Liquid Reaction System Based on Symmetric Aliphatic Ammonium Salts for the Rapid $\mathrm{CO}_{2}$ Fixation with Aziridine to 2Oxazolidinone. Chem. Lett. 2005, 34, 60-61.

32. Gu, Y.; Zhang, Q.; Duan, Z.; Zhang, J.; Zhang, S.; Deng, Y. Ionic Liquid as an Efficient Promoting Medium for Fixation of Carbon Dioxide: A Clean Method for the Synthesis of 5Methylene-3-oxazolidin-2-ones from Propargylic Alcohols, Amines, and Carbon Dioxide Catalyzed by $\mathrm{Cu}(\mathrm{I})$ under Mild Conditions. J. Org. Chem. 2005, 70, 7376-7380.

33. Shi, F.; Deng, Y.; SiMa, T.; Peng, J.; Gu, Y.; Qiao, B. Alternatives to Phosgene and Carbon Monoxide: Synthesis of Symmetric Urea Derivatives with Carbon Dioxide in Ionic Liquids. Angew. Chem. Int. Ed. 2003, 42, 3257-3260.

34. Fujita, S.; Bhanage, B. M.; Arai, M. In Progress in Catalysis Research; Bevy, L. P., Ed.; Nova Science Publishers Inc.: New York, 2005; p. 57.

35. Fujita, S.; Arai, M. Chemical Fixation of Carbon Dioxide: Synthesis of Cyclic Carbonate, Dimethyl Carbonate, Cyclic Urea and Cyclic Urethane. J. Jpn. Petrol. Inst. 2005, 48, 67-75.

36. Zhao, F.; Fujita, S.; Arai, M. Developments and Applications of Supported Liquid Phase Catalysts. 
Curr. Org. Chem. 2006, 10, 1681-1695.

37. Howarth, J.; Hanlon, K.; Fayne, D.; McCorma, P. Moisture Stable Dialklimidazolium Salts as Heterogeneous and Homogeneous Lewis Acids in the Diels-Alder Reaction. Tetrahedron Lett. 1997, 38, 3097-3100.

38. Thomas, J.-L.; Howarth, J.; Hanlon, K.; McGuirk, D. Ferrocenyl imidazolium salts as a new class of anion receptors with $\mathrm{C}-\mathrm{H} \cdots \mathrm{X}^{-}$hydrogen bonding. Tetrahedron Lett. 2000, 41, 413-416.

39. Kim. Y. J.; Varma, R. S. Tetrahaloinate(III)-Based Ionic Liquids in the Coupling Reaction of Carbon Dioxide and Epoxide To Generate Cyclic Carbonates: H-Bonding and mechanistic Studies. J. Org. Chem. 2005, 70, 7882-7891.

40. Sun, J.; Fujita, S.; Zhao, F.; Arai, M. Synthesis of Styrene Carbonate from Styrene Oxide and Carbon Dioxide in the Presence of Zinc Bromide and Ionic Liquid under Mild Conditions. Green Chem. 2004, 6, 613-616.

41. Zhao, F.; Ikushima, Y.; Chatterjee, M.; Sato, O.; Arai, M. Hydrogenation of an $\alpha, \beta$-unsaturated aldehyde catalyzed with ruthenium complexes with different fluorinated phosphine compounds in supercritical carbon dioxide and conventional organic solvents. J. Supercrit. Fluids 2003, 27, 6572.

(C) 2006 by MDPI (http://www.mdpi.org). Reproduction is permitted for noncommercial purposes. 